\title{
Economic impact analysis of current climate change variability and future impacts in agricultural sector of Nepal
}

\author{
D.C. Devkota ${ }^{1}$, K.R. Gosai ${ }^{2}$, D. Devkota ${ }^{1}$ \\ ${ }^{1}$ Integrated Development Society Nepal \\ ${ }^{2}$ Tri-Chandra Multiple Campus, Tribhuvan University, Kathmandu, Nepal
}

\begin{abstract}
Nepal's economy is largely based on agriculture, predominantly small-scale farming, and about half of which is dependent on natural rainfall. In Nepal, agriculture is a highly climate sensitive sector. Historically, the sector has been affected by floods, droughts and erratic rainfall. This study focused on the impacts and economic costs of climate change in agriculture and assessed perceptions of communities of Kaski and Mustang districts on frequency and intensity of hailstorm events over time including their related impacts. Scenario-based impact assessment was used for assessment of longterm impacts and economic costs of climate change. The study used Decision Support System for Agro-technology Transfer (DSSAT) model to analyze the effects of climate on three major crops, namely rice, maize and wheat. The economic loss due to the impacts of climate change in cereals (rice, maize and wheat) was estimated at around US\$336.42 million in the year 2006. Among the respondents, $60 \%$ reported food shortages which made them highly vulnerable due to climate variability. Similarly, $80 \%$ of the respondents mentioned that 20 major hailstorm events have occurred in the vicinity of their communities over the last 35 years (up to 2012) and have caused significant damage to crop production, livestock and infrastructure. DesInventar database reported damage of $75 \%$ to $100 \%$ of the key crops. Crop yield projections indicate a complex mix of increases and decreases in yield which vary over time (in projections in 2030 AD and 2070 AD) and by location (east to west/Terai to Mountains). In the 2030s, there is a net increase in production and values; however, by the 2070s, the impact in agricultural production is expected to reach to US\$ 140 million/year (2014). In terms of research, there are priorities around further work to understand climate uncertainty, the indirect economic costs of these impacts, and early research priorities to address long-term challenges. There is an urgent need to build capacity, with information and awareness raising, monitoring, research, and institutional strengthening.
\end{abstract}

Key words: Climate change, agricultural loss, productivity

\section{Introduction}

Nepal's economy is largely based on the agricultural with predominant small-scale farming and about half of which is dependent on rainfall. Agriculture in Nepal, accounts for approximately one-third of country's GDP and provides employment to two-thirds of the active population and represents $13 \%$ of total foreign trade (CBS, 2012). Agriculture is a highly climate sensitive sector as rainfall and other climatic factors are critical to crop yields. Historically, the sector has been affected by floods, droughts and erratic rainfall and studies indicate that the performance of crop production can largely be explained by climatic variability and temporal weather conditions (Sherchand et al., 2007). It is predicted that agricultural production will also be highly affected by future climate change. This study focused

*Corresponding author, email address: kamal_gosai2002@yahoo.com on the impacts and economic costs of climate change in agricultural sector and assessed perceptions about the frequency and intensity of hailstorm events over time, and their impacts among the communities in Kaski and Mustang.

\section{Materials and Methods Long-term impacts and economic costs assessment}

Scenario-based impact assessment method was used for assessment of long-term impacts and economic costs of climate change. The process started with selection of climate model simulations of future climate change for defined future emission scenarios and then quantification of physical impacts of future changes, and assessing the corresponding economic damages (Carter et al., 2007). The impact analysis was undertaken using impact functions that link climatic parameters to physical impacts, though this is 
often integrated within impact assessment models. This study used down-scaled regional climate model simulation projections for Nepal focusing on a medium-high emission scenario (the SRES A1B scenario (Nakienovi et al., 2000) with interpretation of uncertainty from other models (including available in the DHM portal) and statistically down-scaled climate model results (UCT, 2012). The projection data were then combined with sectoral impact methods and models.

Impact analysis on agriculture sector (covering rice, wheat and maize) was undertaken using a well-known crop simulation model, the Decision Support System for Agro-technology Transfer (DSSAT) (Hoogenboom et al., 2004). DSSAT is a process-based computer model that predicts growth, development and yield as a function of local weather and soil condition (soil-plant-atmosphere dynamics), crop management scenarios and genetic information. The model used daily weather data, soil profile information, and basic crop management data as inputs. The study splits Nepal from east to west horizontally and in terms of elevation into the Terai (plains), Mid-hill and Mountain vertically. Thus, working with nine major aggregation areas, i.e. Solukhombu (East Mountain), Dhankuta (East Mid-hill), Sunsari (East Terai), Mustang (TransHimalayan Mountain), Lalitpur (Central Mid-hill), Rupendehi (Central Terai), Jumla (West Mountain), Surkhet (West Mid-hill), Banke (West Terai). The application used observed crop data for validation, based on Coordinated Varietal Trial (CVT) data (3 years data for rice, one year for maize and four years for wheat). Crop periods were selected to match seasonal timing in the regions. The climate model projections for the time period 1972 - 2070 were used with analysis of yield changes by temperature and precipitation. Additional parameter included in the analysis was $\mathrm{CO}_{2}$ concentration.

The DSSAT model produced estimates the changes in crop productivity, output in tones/hectare. By combining with land area, these changes in productivity can be valued using market prices. Two sets of market prices were potentially relevant for this calculation: world prices and domestic prices. A further sensitivity was also undertaken to look at future prices due to the combination of socio-economic scenarios and global climate change (i.e. on other suppliers and trade effects). The analysis of the effects of future climate change was based on a review of price profiles with climate change to 2100 (Easterling et al., 2007). Similarly, sensitivity analysis used the changes in output cereal prices (Parry et al., 2004) as a proxy for the three commodities.

Static assumptions have been applied for underlying trends (e.g. agricultural productivity improvements, rising population, rising assets at risk). The study used DSSAT model to analyze the effects of climate on three major crops: rice, maize and wheat based on their cultivation practice in eastern (Solukhumbu, Dhankuta and Sunsari), central (Mustang, Lalitpur, Rupandehi) and western (Jumla, Surkhet and Banke) areas of Nepal representing Terai, Hills and Mountains.
For perceptions study, Kaski and Mustang districts were chosen. In Kaski, three VDCs (Village Development Committees (Pumdibhumdi, covering $32 \mathrm{~km}^{2}$; Sarangkot covering $18 \mathrm{~km}^{2}$ and Lumle covering $53 \mathrm{~km}^{2}$ ) were selected and four village communities of Mustang (Lete, Marpha, Jomsom and Kagbeni) were taken as sample area. In both the districts, 96 households from each district were randomly selected to for household survey.

\section{Results and Discussion Impacts and costs of current climate variability Economic impacts of climate variability}

The EM-DAT database (EM-DAT, 2013) reports drought in the year 1972 affected 90,000 people and cost US\$10 million and that of 1979 affected 3.5 million people. There have been a number of relatively large-scale events in recent years, with major droughts in 2006, 2008/9 and 2009/10. The UNWFP (2009) reports that 2009 winter crop harvests were reduced by 40\% (Mountain), 25\% (Hill), and $10 \%$ (Terai) compared to the previous year, due to the dry winter leading to a national decrease in production of wheat and barley (the two major winter crops) respectively by $14.5 \%$ and $17.3 \%$, resulting in an annual cereal deficit of 133,000 metric tons despite excellent summer crop harvests. Early DSSAT modeling in the National Communication (GoN, 2004) reports that temperature rise might increase wheat output in the western region of Nepal, but could lead to a decline in other regions. Rice yields were also generally anticipated to increase up to a certain temperature level. However, potential decreases in yield were reported for maize (a temperature sensitive crop) particularly in Terai.

The 2009 winter drought came after a severe 2006 winter drought combined with extensive summer flooding (resulting in 225,000 metric tons grain deficit). Given the context of low stock levels prior to that of 2009 (down by 20\% compared to 2008) the result was a serious deterioration in food availability, particularly in the most hard hit and isolated regions of the Mid- to Far-Western Hills and Mountains (UNWFP, 2009). The 2009/2010 drought event is reported to have led to an 11\% loss of rice yield and $7 \%$ loss in wheat and maize resulted in a grain deficit of 400 metric tons (Poudel et al., 2011).

Drought events can be regional or localized as well as varying across the country, as shown in the NAPA mapping (Fig. 2). In addition, there is massive welfare cost of drought, especially when it affects large number of people. The EM-DAT International Disaster Database (2013) reports that the 2009 drought affected 303,000 people and the 2006 drought affected around 200,000 people. Almost one million people were made highly or severely food insecure by the 2006 and 2009 events (UNWFP, 2009).

\section{梅 TU-CDES}




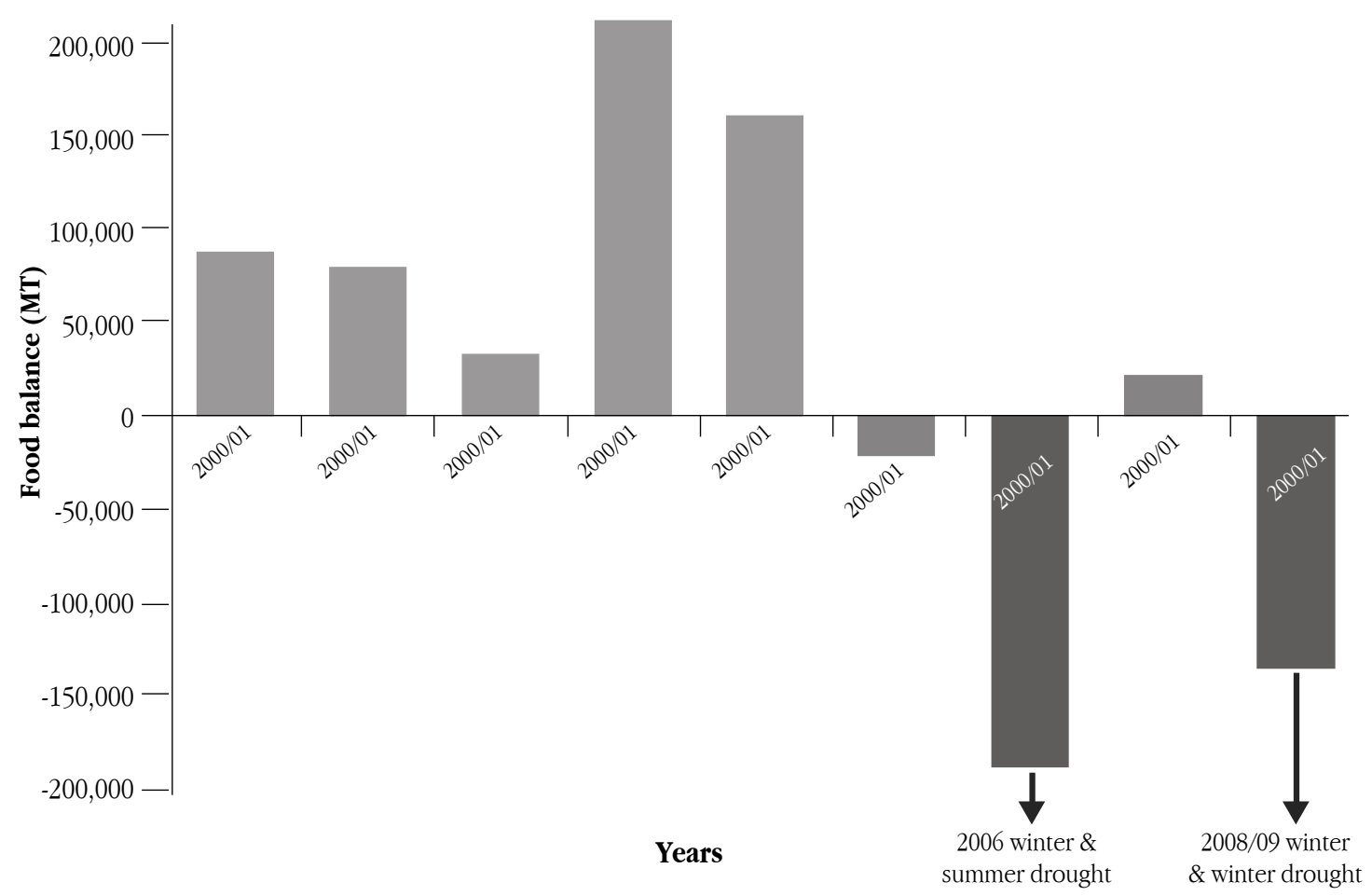

Figure 1 Nepal annual cereal production surplus/deficit (Source: UN WFP, 2009)

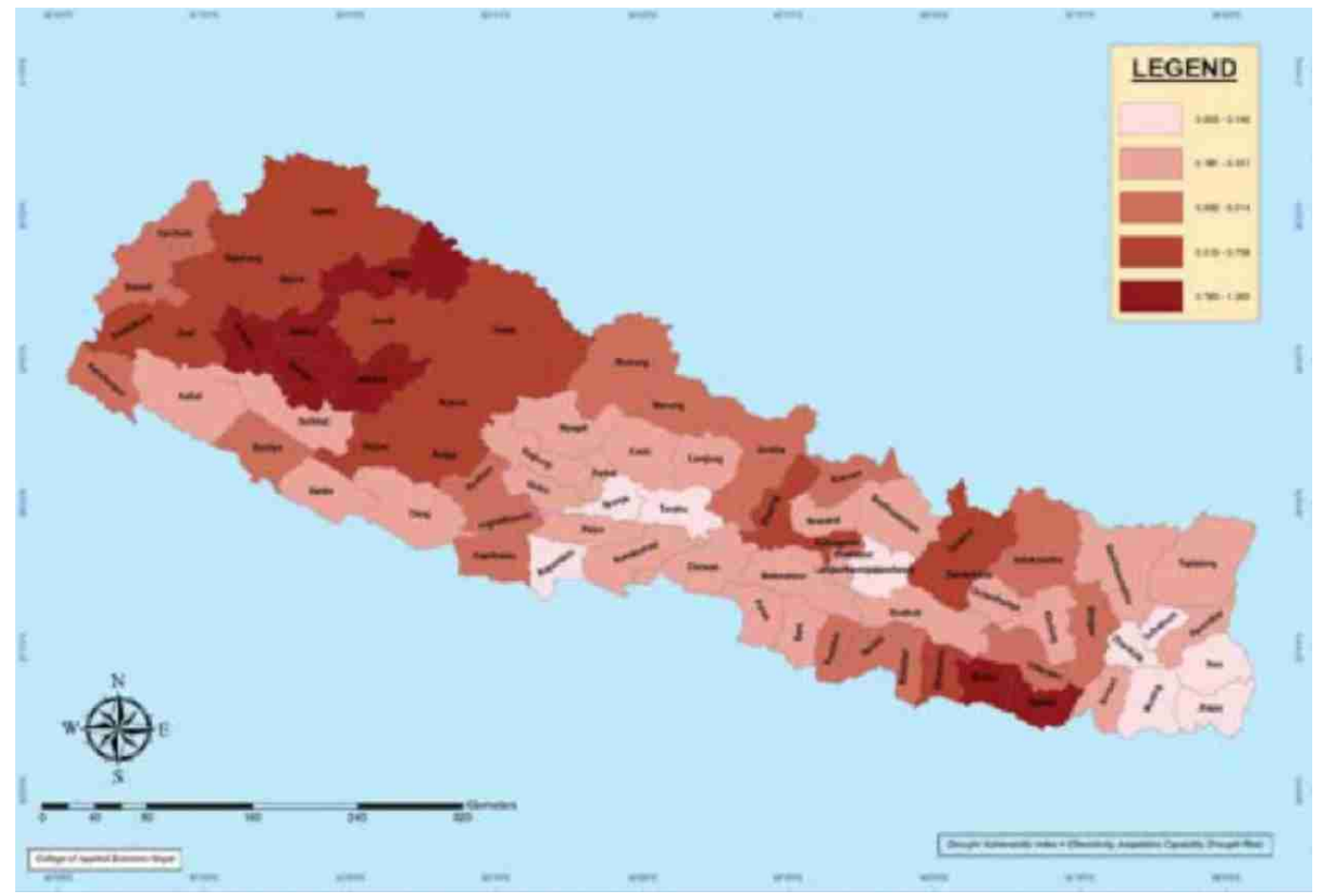

Figure 2 Drought vulnerability map (GoN, 2010) 
Table 1 Drought related agricultural loss and its direct economic costs in Nepal

\begin{tabular}{lrrrr}
\hline & \multicolumn{2}{c}{ Lost production (million tonnes) } & \multicolumn{2}{c}{ Economic cost (US\$) } \\
\hline Wheat & 2006 & 2009 & 2006 & 2009 \\
Barley & 226,000 & 110,000 & $65,148,000$ & $32,040,000$ \\
Rice & 5,000 & - & $1,068,000$ & \\
Maize & 445,000 & - & $270,204,000$ & \\
Total & - & 130,000 & & $33,108,000$ \\
& & & $\mathbf{3 3 6 , 4 2 0 , 0 0 0}$ & $\mathbf{6 5 , 1 4 8 , 0 0 0}$ \\
\hline
\end{tabular}

The direct economic cost of these recent droughts can be estimated by valuing the lost agricultural output. In 2006, the drought resulted in an $11 \%$ loss in terms of rice yields and a $7 \%$ loss in wheat and maize, whilst in 2009 , there was a $15 \%$ and $17 \%$ loss in wheat and barley yields, respectively. The economic costs are presented in Table 1, using the international market prices of 2006 and 2009. As shown, they equate to $1.9 \%$ and $0.4 \%$ of current GDP for the two events.

It should be noted that these estimates do not capture the indirect costs associated with lost production such as the effects resulting from lower household incomes on regional economy and the macro-economy. These indirect effects are expected to exert powerful negative multiplier effects. Likewise, wider health and welfare effects of food insecurity, wider disruption and indirect costs, and macroeconomic effects are not included, which are likely to underestimate the full economic costs. As above, it is possible the full costs of these events could have been 25 to $100 \%$ larger than the direct costs alone.

\section{Impact of current climatic variability}

Agricultural production in Nepal varies with temperature and rainfall, and as there is high annual rainfall variability in Nepal, this leads to an additional set of impacts from climatic uncertainties. The DHM/APN (Sherchand et al., 2007) study used DSSAT and mentioned various impacts across crop types and three physiographic regions with climate change. For rice, there were broad increases in yields projected across the temperature and rainfall changes, though with a lower relative increase with higher temperature changes in the Terai. For wheat, yield changes were more varied, with some reductions yield in the Terai but favorable changes reported in the mountains. For maize, projected yields declined in the Terai and Hill regions with higher temperatures, though there were positive effects in the Mountains. The study also highlighted that many of the crops are particularly vulnerable to variability and droughts in key stages of development ( particularly pre-monsoon). Overall the projections showed that Nepal could move from a nation of marginal surplus under a baseline normal scenario to a case where supply and demand only just balanced under the climate change scenario (assuming no adaptation). Rai et al. (2011) also using the DSSAT model, looked at rice production in Nepal and reported that modest temperature increases (minimum temperature) had positive effects, but above $2^{0} \mathrm{C}$, negative impacts start to arise.

A recent application of DSSAT was also undertaken for Nepal as part of the PPCR scoping phase in agriculture (PWC, 2012), which also used for other crop models and considered a wider range of crops. This study also reports high crop yield reductions in the Terai for all three main crops, even in the 2030s, with a stronger impact on maize.

This research reported changes in sowing and planting dates/time of crops and lands also having varying suitability to existing and new crops. Furthermore, there are anecdotal reports of more irregular rainfall patterns, which are making rice seedlings transplantation more difficult compelling farmers to gradually change crops from rice to less water-demanding crops such as sugarcane or forage crops. Similarly, changes in the reliability of stream flow and particularly more intensive and potentially erratic monsoon rainfall (and pre-monsoon rains) have played an important role as well. These trends are further highlighted by the case studies described below.

\section{Case study I: Impact of hailstorms on crop production in Kaski District of Western Nepal}

Kaski district experiences unusual rainfall patterns, with high rainfall and decreased winter monsoon rains. There is also an impact of hailstorms, particularly on agriculture. According to the Nepal Disaster Report (MoHA, 2011), the most frequently occurring disaster during summer months (March/April and October) is hailstorm. In addition to summer crops, hailstorms can also damage winter crops, especially in the mountainous areas of the country. Although most hail is relatively small in size, there have been cases of larger hail stones, which have caused extensive damage to standing crops and even inflicted injuries which at times have caused death of crops. The major damage from such storms has been recorded in eastern Nepal (1980) and mid-western Nepal (1983).

The Disaster Inventory System (DesInventar) recorded 585 hail events across Nepal in the period between 1971 and 2007 (Fig. 3). Nearly 40\% (232 events) of the events occurred in the western region. There is some indication of an increasing trend in the number of hailstorm events over the past three decades, though

\section{㓱TU-CDES}




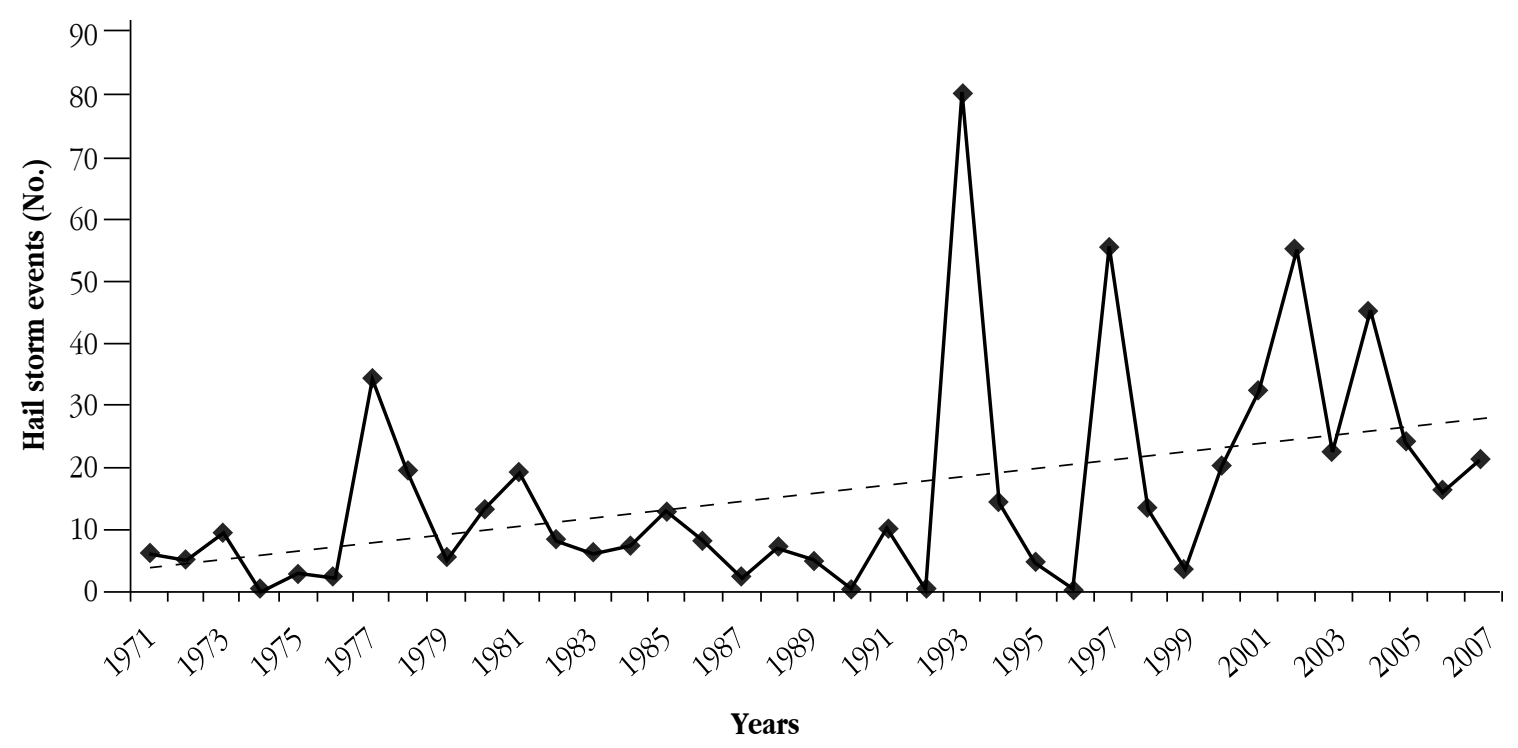

Figure 3 The total number of hail storm events in Nepal from 1971-2007 (Source: DesInventar, 2013)

some caution is needed in interpreting these events over time. From 1971 to 2007, 55 hail events have been recorded in Kaski district. Out of total, $60 \%$ of the respondents reported food shortages which made them highly vulnerable to climate variability. Similarly, any impacts that reduce agricultural productivity or damage crops (food and cash crops) have profound impacts on livelihood.

Out of 94, 75 respondents believed that hailstorms have been occurring more frequently in recent years. They mentioned that 20 major hailstorm events have occurred in the vicinity of their community over the last 35 years (up to 2012) and have caused significant damage to crop production, livestock and infrastructure (including water tanks, pipelines, and window panes). Communities also mentioned that human deaths and injuries have occurred, although relatively rare. The case study found a strong community perception that these events have been increasing in frequency and intensity. Respondents estimated that losses ranged anywhere from an average value of USD 100 to up to USD 620 per household during any particular hailstorm event.

Of the 55 events in Kaski District, DesInventar database reported high damage to wheat, maize and rice crops in various years, as well as to vegetables, oranges and winter crops. The events are reported to inflict damages to 75 to $100 \%$ of the key crops (e.g. in some areas in 1977, 1980, 1985, 1986, 1087, 1988, 1995, 1997, $1998,1999,2002,2004)$. The damage in 1997 was reported to be approximately US\$2 million, due to extensive lossof rice and millet (around 50\%) and a similar amount in 1998. The damages in 1999 are reported at US $\$ 5$ million due to the loss of vegetables, crops and rice. The database also records 13 human deaths from hailstorms in 2005. Two implications have been projected:

a. While data on the economic costs is partial, the major damage to crop harvests are high in some years, ranging from 50\%$100 \%$ of the crop damage and large economic costs.

b. While the future pattern of extreme events and heavy precipitation is uncertain, heavy precipitation events and their intensity are likely to increase during the monsoon.

\section{Case study II: 'Buckwheat farming in Mustang'}

Buckwheat is an important crop, with almost all households cultivating the crop. However, buckwheat production decreased over the last decade due to change in climatic parameter. Increment in time duration to grow buckwheat, decline in productivity and appearance of numerous pests were reported in conjunction to climate change. This is consistent with studies that indicate crop shading conditions and temperature variability affect the viability of pollen and seed, and bud formation is reduced as temperature increases (Wang \& Campbell, 2004).

The respondents perceived that flash floods and landslides have increased with increasing precipitation (including increased intensity). These changes match meteorological observations of increasing intensity and duration of rainfall.

\section{Impacts of future climate change on agriculture}

Analyzing the impacts of climate change on rice production reveals interesting results. The most of the rice is currently produced in the Terai, so changes in production in this region is especially important in terms of national production (Fig. 5). 
The results show a complex mix of increase and decrease in yield which varies over time (2030s and 2070s) and by location (east to west/Terai to Mountains).

The general trend for impacts of climate change on maize is more differentiated than rice. In Terai region, there is an initial increasing production trend (in the 2030s) for the west and central region (but not in the east), followed by a sharply decreasing trend (20\%) in the west in the long-term (2070s) (note: this is already a dry region).

In the hills, there is an increasing yield in the short-term (2030s), as well as in the long-term (2070s) in the east and central regions, but a small decline in the yield in the west in the long-term is observed.

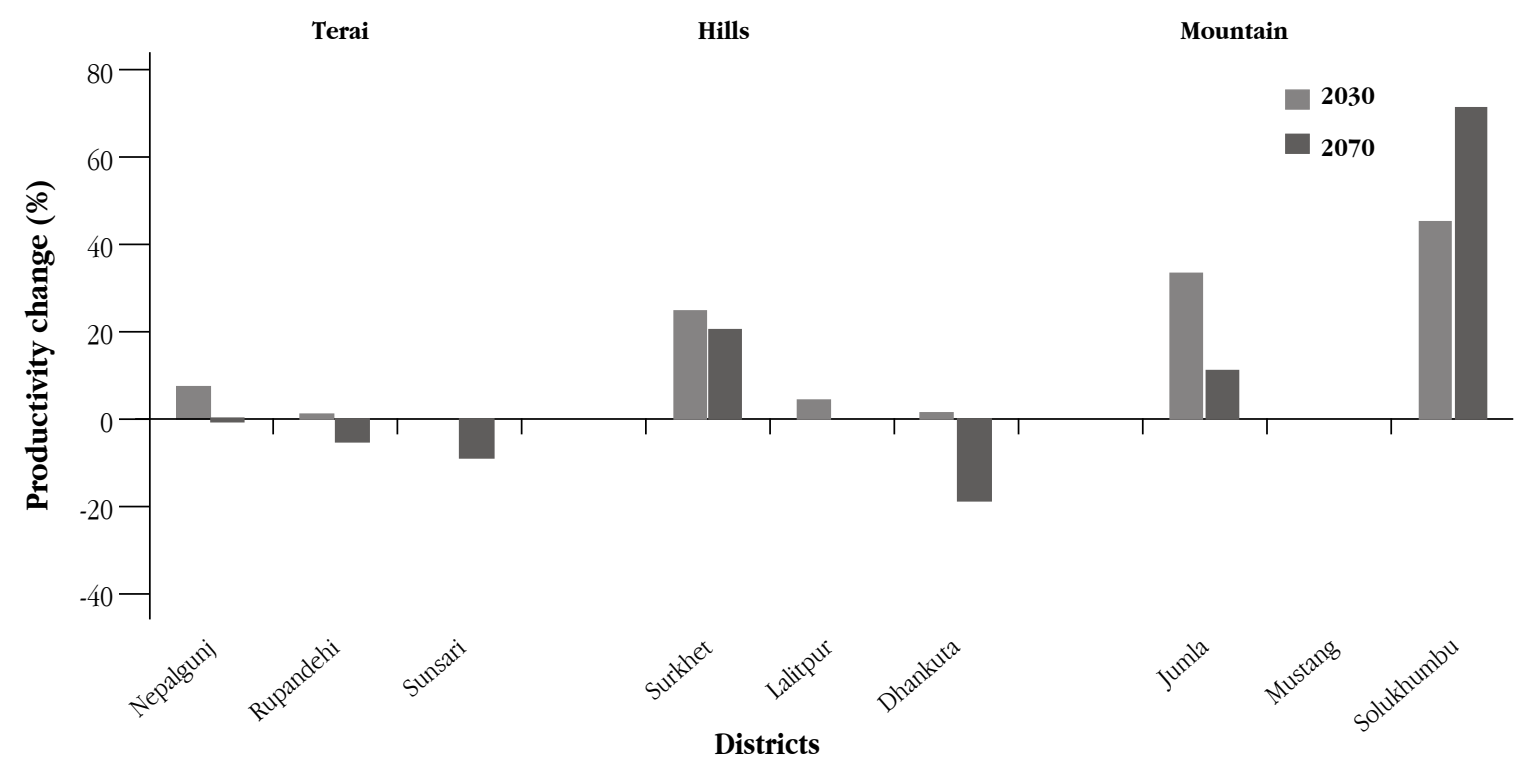

Figure 4 Percentage change in rice yield ( $\mathrm{kg} / \mathrm{ha}$ ) from climate change, relative to baseline

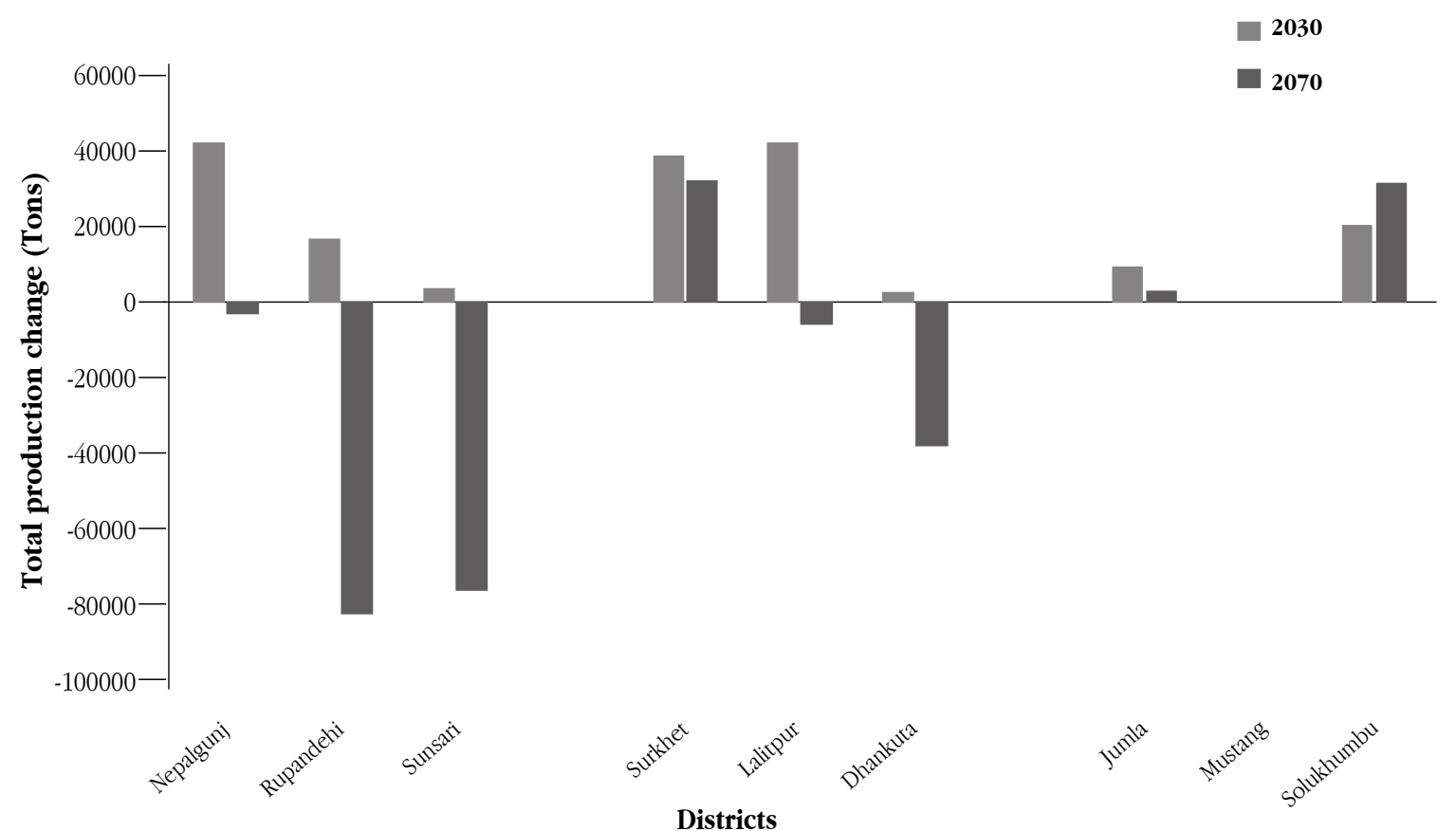

Figure 5 Total change in rice yield from climate change (based on production area), relative to baseline

\section{TH-CDES}




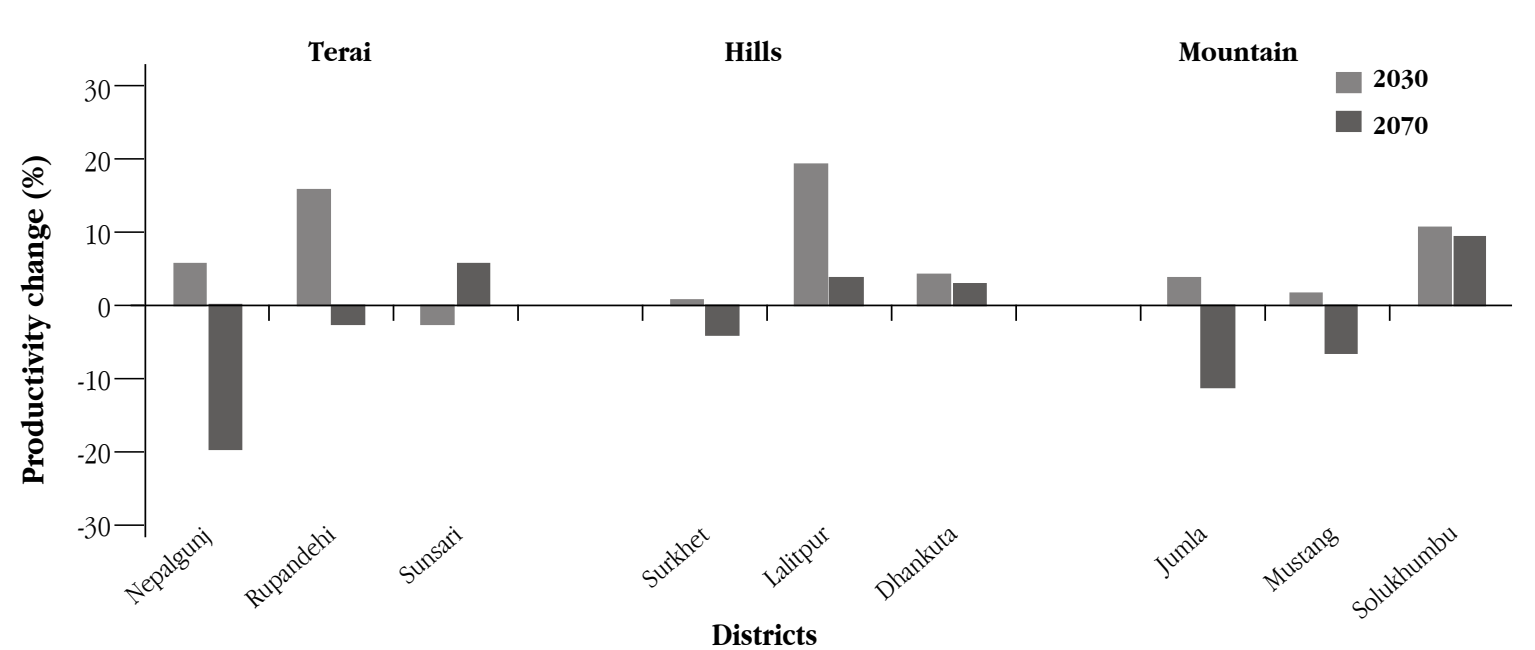

Figure 6 Percentage change in Maize yield ( $\mathrm{kg} / \mathrm{ha}$ ) from climate change, relative to baseline

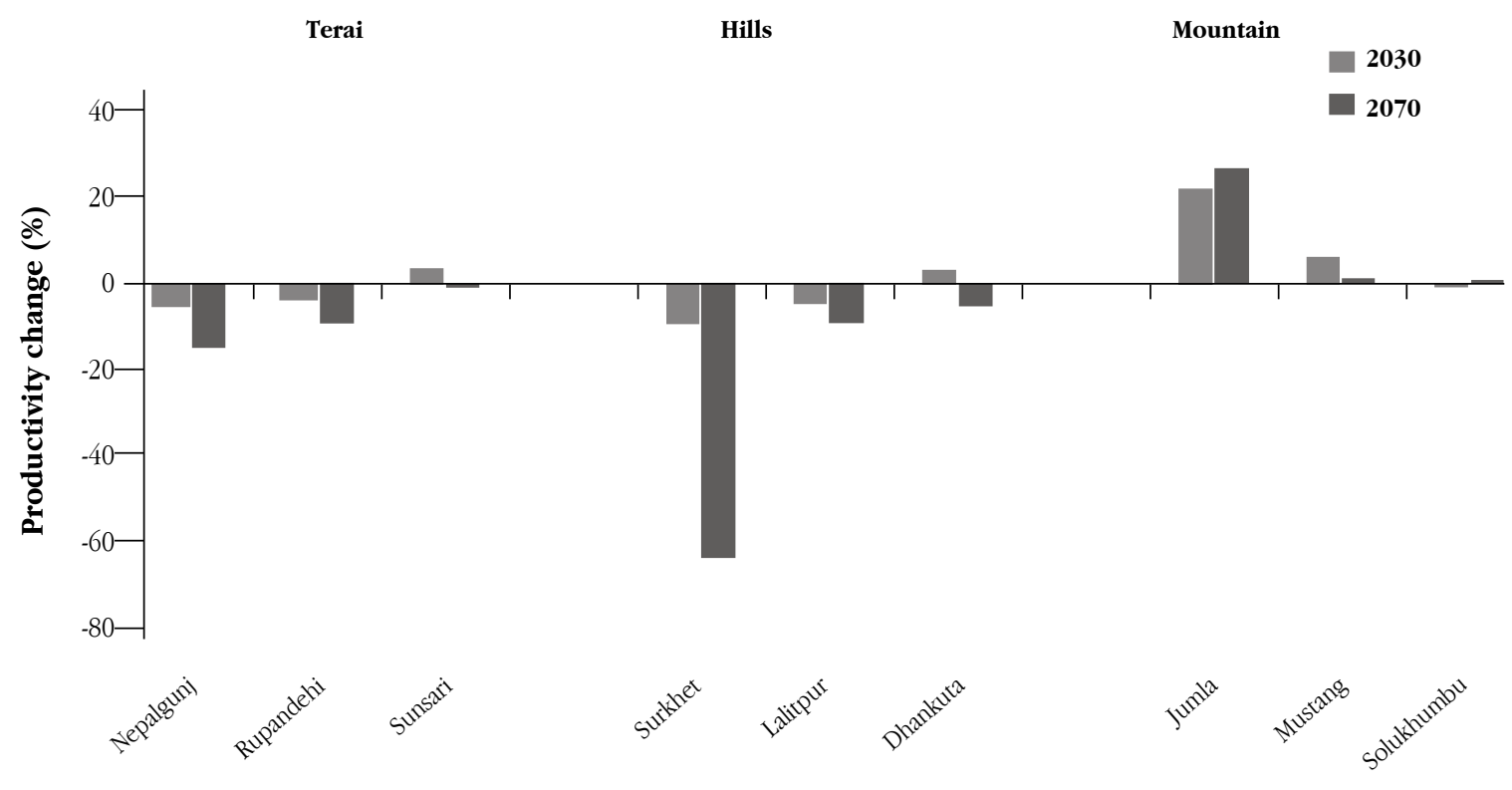

Districts

Figure 7: Percentage change in wheat yields ( $\mathrm{kg} / \mathrm{ha}$ ) from climate change, relative to baseline period

In the mountains, in the short-term (2030s) there is a strong increasing trend across the regions (especially in the east). In the long-term (2070s), there is reduction of yield in western and central region.

With regards to wheat, an initial increase in production is projected for 2030, there is potential of large decrease in wheat production in the central and western Terai in the long-term (2070s). In central and western region, these large decreases are driven by higher temperatures. For the hills, there is a mixed impact in the 2030s, though decrease in yields is found in all areas in the 2070s. There is a high decline in the western hills particularly (though some care should be taken in interpreting this finding, as the reason for the fall needs to be further explored). In the mountains, there is potential of large benefits in the west (and to a lesser extent the central areas) with only modest changes in the central region.

The analysis assumed no change in prices in future, i.e. it assumed 2010 prices also for 2030s and 2070s. It is noted that future world prices for agriculture (as over the time periods here) are highly 

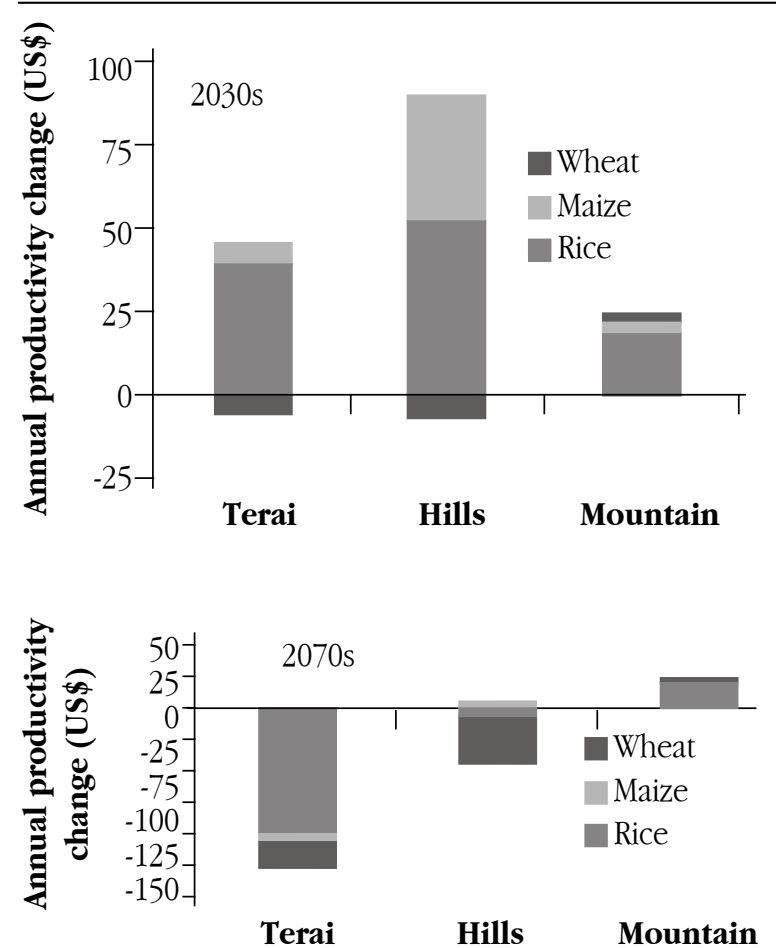

Figure 8 Total net costs from changes in agricultural production from climate change for the (above) and (below) (undiscounted current prices)

uncertain, and will change with future demand and socio-economic development. These future prices and trade flows will also change due to the impacts of climate change on agricultural productivity, both in individual countries and at the aggregate global level.

The overall finding shows that in $2030 \mathrm{AD}$ there will be a net increase in production and values. However, by the 2070 s there are impacts in terms of agricultural productivity, which could total upto US\$140 million/year (current prices). This is equivalent to around $0.8 \%$ of current annual GDP. This analysis assumes that current crop prices will not change in the future, i.e. it assumed the same prices for 2010, 2030s and 2070s. These future prices and trade flows will also change due to the impacts of climate change on agricultural productivity in individual countries and at the aggregate global level. Such future changes have not been taken into account, and would require a global economic agricultural modeling system to assess.

\section{Conclusion}

The impacts of climate change on agricultural is potentially large, excluding the possible impact of various types of autonomous and planned adaptation. However, these results are highly sensitive to future climate projections.

There is a direct economic cost of current climate variability in Nepal, which is very high. in terms of its impact both on GDP and household economy. These impacts have major implications on livelihoods, affecting hundreds of thousands of people in the major extreme years. There is a strong seasonal dimension to these impacts, with high costs from excess rainfall during the monsoon season (from floods) and from low rainfall during the dry season (due to low flows and hydro-electricity outages). The economic costs of climate variability vary from year to year due to cyclic nature of climate variability.

The combined effects of the current climate vulnerability and future climate change could therefore be large enough to prevent Nepal from achieving economic growth, development and poverty reduction targets. One of the largest impacts from climate change could be in the form of increased variability (rather than gradual changes) in different years. Therefore, agriculture development planners should plan safety nets such as food, seed and germ plasm banks or cushioning mechanism such as risk mitigating irrigation, cropping pattern change and replacement cropping strategies.

\section{Acknowledgements}

The authors are thankful to Integrated Development Society-Nepal (IDS Nepal) for the data, and to Climate and Development Knowledge Network (CDKN), DFID UK for funding the research work and to all other research partners for making the study results accessible to the authors.

\section{References}

Carter, T., Jones, R. N., Lu, X., Bhadwal, S., Conde, C., Mearns, L., O'Neil, C.B., Rounsevell, A.D.M., \& Zurek, B.M. (2007). New Assessment Methods and the Characterisation of Future Conditions. Cambridge University Press, Cambridge, UK, pp 133-171.

CBS (2012). National Account Estimate 2011/2012. Govt. of Nepal National Planning Comission, Kathmandu, Nepal.

Easterling, W., Aggarwal, P., Batima, P., Brander, K., Erda, L., Howden, MKirilenko, A., Morton, J., Soussana, J.F., Schmidhuber, J., \& Tubiello, F. (2007). Climate Change 2007: Impacts, Adaptation, and Vulnerability. 2007: Food, Fibre and Forest Products. Cambridge University Press, Cambridge, UK, 273-313.

EM-DAT (2013): The OFDA/CRED International Disaster Database. www.emdat.be - Universitécatholique de Louvain, Brussels, Belgium.

GoN (2004) Initial National Communication to the Conference of the Parties of the United Nations Framework Convention on Climate Change. Ministry of Population and Environment, Kathmandu, Nepal.

MoE (2010). National Adaptation Programme of Action (NAPA). Government of Nepal, Ministry of Environment, Kathmandu, Nepal.

Hoogenboom, G., Jones, J. W., Wilkens, P. W., Porter, C. H., Batchelor, W. D., Hunt, L. A., Boote, K.J., Singh, U., Uryasev, O., Bowen, W.T., \& Gijsman, A. J. (2004). Decision support system for agrotechnology transfer version 4.0, (CD-ROM). University of Hawaii, Honolulu, HI .

\section{喻TU-CDES}

